\title{
ANALISIS MODAL PINJAMAN DALAM MENINGKATKAN LABA PADA PEDAGANG KAKI LIMA DI PALOPO
}

\author{
Ahmad Suardi H \\ Sekolah Tinggi Ilmu Ekonomi Muhammadiyah Palopo \\ E_Mail: ahmadsuardi@stiem.ac.id
}

\begin{abstract}
Abstrak: Tujuan jangka panjang penelitian ini adalah adanya upaya yang terencana terhadap Penggunaan Modal pinjaman yang tepat sasaran untuk meningkatkan laba pada pedagang kaki lima (PKL) di Kota Palopo. Target khusus yang ingin dicapai dalam penelitian ini adalah untuk mengetahui dan menganalisis penggunaan modal pinjaman dengan tepat sasaran agar dapat meningkatkan laba pada pedagang kaki lima (PKL).

Penelitian ini akan dilaksanakan pada Pedagang kaki Lima Di Kota Palopo, data dalam penelitian ini merupakan data yang bersumber dari hasil observasi, wawancara dan dokumentasi dengan para pedagang kaki lima di kota palopo. Perkembangan laba para pedagang kaki lima melalui penggunaan modal pinjaman dianalisis menggunakan pendekatan metode analisa yang relevan yakni menggunakan Rasio Profitabilitas dan Rasio Solvabilitas.

Rencana kegiatan penelitian ini dimulai dari studi kepustakaan (literatur), penentuan sampel, penentuan design penelitian, penentuan lokasi dan waktu penelitian, instrumentasi penelitian, uji validitas, pengumpulan data, analisa data, dan membuat kesimpulan.
\end{abstract}

Kata kunci: Teknik Analisa, modal Pinjaman, Laporan Keuangan

\section{PENDAHULUAN}

Keberhasilan sektor swasta, sangat ditentukan oleh tiga komponen yang saling berhubungan satu sama lain yaitu pemerintah sebagai penentu kebijakan untuk menyediakan sarana dan prasarana, masyarakat sebagai pembentuk pasar, dan pelaku bisnis yang menghasilkan barang atau jasa sesuai dengan kebutuhan pasar. Setiap perusahaan atau jenis usaha baik itu dalam bidang jasa maupun barang membutuhkan modal, baik modal sendiri maupun modal pinjaman. Pemerintah kota diharapkan meningkatkan pelayanan kepada sektor swasta agar berperan dalam pembangunan secara optimal.

Ketiga komponen tersebut diharapkan dapat bekerjasama dengan baik agar mampu meningkatkan pertumbuhan perekonomian negara secara normal dan kontinyu. Apabila pelaku bisnis berhasil, maka pendapatan pemerintah akan bertambah dari pajak, demikian pula sebaliknya
\end{abstract}

akan berkurang jika pelaku bisnis gagal, bahkan dapat membebani negara.

Mengingat terdapat potensi di dalam sektor informal baik berupa pedagang kaki lima maupun pedagang keliling tersebut, perlu adanya pengembangan ilmiah yang memberikan pemahaman dan landasan baru bagi pedagang kaki lima yang keliling untuk mendapatkan capaian kinerja yang optimal. Evaluasi terhadap Kinerja Pedagang Kaki Lima (PKL) dapat juga dilakukan dengan menganalisa laporan keuangan yang diaudit kemudian dianalisis dengan menggunakan beberapa ratio yang relevan.

Fungsi analisa ratio modal pinjaman adalah membiasakan pemilik usaha membuat keputusan atau pertimbangan tentang apa yang perlu dicapai dimasa yang akan datang? Bagaimana prospek yang dihadapi dimasa yang akan datang? Fokus dari analisis ratio modal pinjaman berbeda-beda, baik kepentingan khusus maupun kepentingan umum. 
Sehubungan dengan uraian di atas, maka Pedagang Kaki Lima (PKL) berusaha meningkatkan laba setiap tahun dengan cara menempatkan modal pinjaman dalam jumlah yang tepat. Jika Pedagang Kaki Lima (PKL) mampu meningkatkan efisiensi penggunaan modal, maka usaha yang dijalankan dapat memperoleh laba yang optimal, sehingga mampu mempertahankan kelangsungan hidupnya bahkan menambah kekayaan. Sehingga yang menjadi pokok permasalahan dalam penelitian ini adalah : Apakah Modal pinjaman berpengaruh terhadap peningkatan laba pada Pedagang Kaki Lima (PKL) Kota Palopo ?

\section{METODE DAN BAHAN}

Metode penelitian meliputi (a) studi kepustakaan (literatur), (b) penentuan data primer dan data sekunder (c) penentuan design penelitian, (d) penentuan lokasi dan waktu penelitian, (e) instrumentasi peneltian, (f) uji validitas dan reliabilitas kuisioner, (g) pengumpulan data, (h) analisa data, (i) membuat kesimpulan.

Data yang dikumpulkan dalam penelitian ini meliputi data primer dan data sekunder, baik kualitatif maupun kuantitatif. Data kuantitatif diperoleh dalam bentuk mentah dari catatan perkembangan laba pedagang kaki lima dalam kurun waktu tertentu berdasarkan modal usaha yang dimiliki. Data kualitatif merupakan data yang disajikan bukan dalam bentuk angka melainkan hasil observasi dan wawancara terhadap perkembangan usaha pedagang kaki lima di Kota Palopo.

Seluruh data yang terkumpul ditabulasi sesuai dengan kategorinya, lalu dianalisis sesuai kebutuhan penelitian. Untuk mengetahui perkembangan modal usaha para pedagang kaki lima maka dilakukan analisis modal dan peningkatan laba dengan menggunakan Rasio Profitabilitas dan Rasio Solvabilitas.

\section{HASIL DAN PEMBAHASAN}

\section{Perkembangan pedagang Kaki Lima di Palopo}

Penjual atau pedagang dapat dikategorikan dalam beberapa kategori, ada penjual atau pedagang besar-besaran ada juga penjual atau pedagang kecil-kecilan atau sering disebut dengan pesagang kaki lima. Penjual atau pedagang kaki lima adalah penjual atau pedagang yang menjajakan jualannya di pinggir jalan atau sambil jalan, penjual atau pedagang kaki lima ini biasanya banyak melakukan aktivitas di pasar-pasar tradisional seperti pada Pusat Niaga Palopo.

Pedagang kaki lima pada umumnya merupakan perpaduan penduduk kota palopo dengan kaum pedagang dengan pendidikan rendah, usia kerja produktif, dan di dominasi oleh kaum laki-laki atau perempuan yang sudah berkeluarga, yang dalam kegiatannya seringkali melibatkan keluarga dan kerabat sendiri sebagai tenaga kerja pembantu.

\section{Laporan keuangan}

Untuk lebih jelasnya, maka laporan keuangan dalam laba rugi tahun 2015 dapat dilihat sebagai berikut yaitu : 


\section{Pedagang Makanan}

\section{LAPORAN LABA RUGI PEDAGANG \\ MAKANAN \\ 31 Desember 2015}

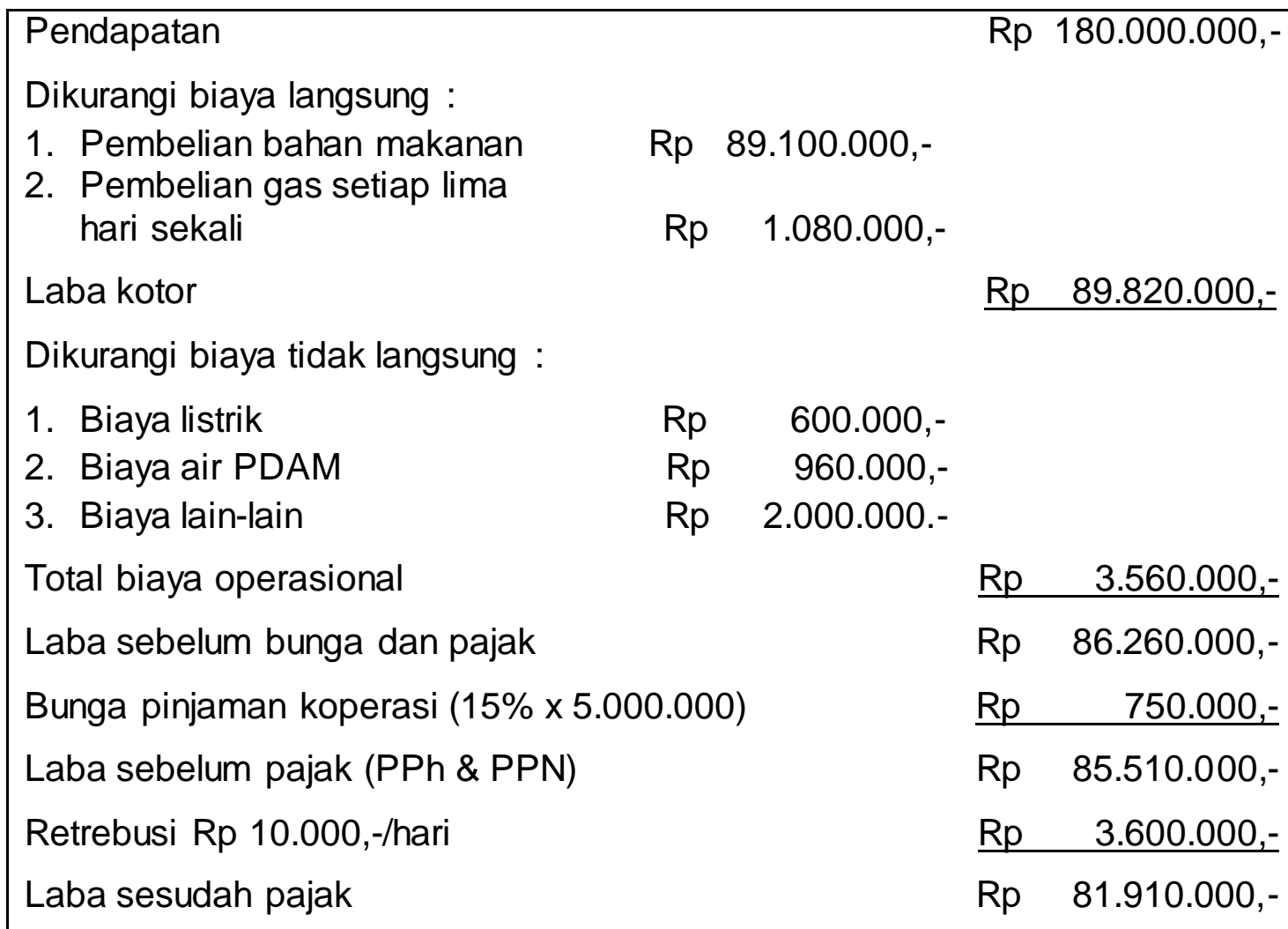

Laporan laba rugi untuk pedagang makanan pada tahun 2015 di atas dapat dirinci dimana : Pendapatan yaitu, jumlah makana yang dijual tahun 2015 x harga per mangkok bakso x 360 hari yaitu; Bakso yang terjual perhari sebanyak 50 dan harga bakso Rp 10.000,-/mangkok bakso yaitu, 50 x Rp 10.000,-= Rp 500.000,-x 360 hari $=$ Rp 180.000.000,--.

Sehingga pendapatan pedagang makanan tahun 2015 sebesar Rp 180.000.000,-. Untuk biaya langsung pembelian bahan makanan $\mathrm{Rp}$ 89.100.000,- dan pembelian gas setiap 5 hari sekali Rp 1.080.000,-. Sehingga pada pedagang makanan tahun 2015 dapat memperoleh laba sebesar Rp 81.910.000,-.
Untuk mengetahui jumlah asset pada pedagang makanan dapat dilihat pada laporan perhitungan neraca tahun 2015 adalah sebagai berikut : 


\title{
NERACA PEDAGANG MAKANAN \\ 31 Desember 2015
}

\author{
AKTIVA \\ AKTIVA LANCAR \\ 1. Kas \& Bank \\ Rp 20.000.000,- \\ 2. Persediaan \\ Total Aktiva Lancar \\ Rp 23.410.000 + \\ Rp 43.910.000,-

\section{AKTIVA TETAP} \\ 1. Bangunan (tenda) \\ Penyusutan \\ Nilai buku \\ Rp 1.300.000,-

$\frac{\mathrm{Rp}}{\mathrm{Rp}} \frac{(300.000)-}{1.000 .000,-}$ \\ 2. Peralatan \\ Rp 10.000.000,- \\ Penyusutan \\ $\frac{\operatorname{Rp}}{\operatorname{Rp}} \frac{(1.500 .000)-}{8.500 .000,-}$ \\ 3. Kendaraan (motor) \\ \begin{tabular}{cc}
$R p$ & $16.000 .000,-$ \\
$R p$ & $(2.500 .000)-$ \\
\hline$R p$ & $13.500 .000,-$
\end{tabular} \\ Nilai buku \\ Total Aktiva Tetap \\ TOTAL AKTIVA \\ Rp 23.000.000+ \\ Rp 66.910.000,-

\section{PASSIVA} \\ UTANG LANCAR \\ Utang Koperasi \\ TOTAL UTANG \\ Rp 7.000.000,- \\ Rp 7.000.000,-

\section{MODAL} \\ Modal awal \\ Laba bersih \\ Diambil pemilik \\ Laba ditahan \\ Rp 81.910.000,- \\ Rp 10.000.000,- \\ Total Modal \\ TOTAL PASSIVA \\ Rp 32.000 .000

\section{Rp $\quad 49.910 .000+$}

\section{Rp 59.910.000+ Rp 66.910.000,-}

Pada pedagang makanan tahun 2015 memiliki total passive sebesar $\mathrm{Rp}$ 66.910.000,terdiri atas utang koperasi Rp 7.000.000,- dan laba bersih sebesar Rp 81.910.000,- diambil oleh pemilik usaha sebesar Rp 32.000.000,- sehingga saldo laba ditahan sebesar Rp 49.910.000,- total asset sebesar Rp 66.910.000,- terdiri atas persediaan senilai Rp 23.410.000,- dan kas sebesar
Rp 1.300.000,- dengan penyusutan $\mathrm{Rp}$ 300.000,sehingga nilai buku sebesar Rp 1.000.000,- dan pembelian peralatan Rp 10.000.000,- dengan penyusutan sebesar Rp 1.500.000,- sehingga nilai buku Rp 8.500.000,- selanjutnya kendaraan seharga Rp 16.000.000,- dengan penyusutan per tahun sebesar Rp 2.500.000,- sehingga terdapat nilai buku sebesar Rp 13.500.000,- 
Pedagang Logam

LAPORAN LABA RUGI PEDAGANG

LOGAM

31 Desember 2015

\begin{tabular}{|c|c|}
\hline Pendapatan & Rp 135.000.000,- \\
\hline $\begin{array}{l}\text { Dikurangi biaya langsung : } \\
\text { Pembelian barang dagang } \\
\text { Laba kotor }\end{array}$ & $\begin{array}{cc}R p & 60.000 .000+ \\
R p & 75.000 .000,-\end{array}$ \\
\hline $\begin{array}{l}\text { Biaya tidak langsung : } \\
\text { Biaya lain-lain } \\
\text { Laba sebelum bunga \& pajak } \\
\text { Bunga pinjaman koperasi }(15 \% \times 10.000 .000,-) \\
\text { Laba sebelum pajak (PPh \& PPN) }\end{array}$ & $\begin{array}{cr}\mathrm{Rp} & 7.200 .000- \\
\mathrm{Rp} & 67.800 .000,- \\
\mathrm{Rp} & 1.500 .000_{-} \\
\mathrm{Rp} & 66.300 .000,-\end{array}$ \\
\hline $\begin{array}{l}\text { Retrebusi } 5.000 / \text { hari } \\
\text { Laba sesudah pajak }\end{array}$ & $\begin{array}{cc}\mathrm{Rp} & 1.800 .000- \\
\mathbf{R p} & \mathbf{6 4 . 5 0 0 . 0 0 0},\end{array}$ \\
\hline
\end{tabular}

\section{NERACA PEDAGANG LOGAM} 31 Desember

AKTIVA
AKTIVA LANCAR
1. Kas
2. Persediaanbarang
Total Aktiva Lancar
AKTIVA TETAP
1. Peralatan (lemari)
$\quad$ Penyusutan
$\quad$ Nilai buku
Kendaraan (motor)
$\quad$ Penyusutan
$\quad$ Nilai buku
Total Aktiva Tetap
TOTAL AKTIVA

PASSIVA
UTANG LANCAR
Utang koperasi
TOTAL UTANG
MODAL
Modal awal
Laba bersih
Diambil pemilik
Laba ditahan
Total modal akhir
TOTAL PASSIVA

Rp 20.000.000, -

$\underline{\text { Rp } 13.000 .000+}$

Rp 33.000.000, -

Rp 3.000.000,-

$\mathrm{Rp} \quad(500.000)-$

Rp 2.500.000,-

Rp 16.000.000,-

$\operatorname{Rp}(2.000 .000)-$

Rp 14.000.000,-

Rp 16.500.000 -

Rp 49.500.000,-

Rp 15.000.000,-

Rp 15.000.000,-

Rp 10.000.000,-

Rp 64.500.000,Rp 40.000.000 -

Rp $24.500 .000+$ 
Laporan laba rugi untuk pedagang logam pada tahun 2015 di atas dapat dirinci dimana : Pendapatan; yaitu jumlah logam yang terjual tahun 2015 x harga 1 buah logam x 360 hari yaitu 15 x $\operatorname{Rp} 25.000=\operatorname{Rp} 375.000 \times 360$ hari $=R p$ 135.000.000,-. Sehingga pendapatan pedagang logam tahun 2015 sebanyak Rp 135.000.000,- dan memperoleh laba tahun 2015 sebesar Rp 64.500.000,-.

Pada pedagang logam tahun 2015 memiliki total passive sebesar Rp 49.500.000,- terdiri atas utang koperasi Rp 15.000.000,- dan laba bersih sebesar Rp 64.500.000,- diambil oleh pemilik sebesar Rp 40.000.000,- sehingga saldo laba ditahan sebesar $\mathrm{Rp}$ 24.500.000,- Total asset sebesar Rp 49.500.000,- terdiri atas persediaan senilai Rp 13.000.000,- dan kas sebesar Rp 20.000.000,- peralatan $\mathrm{Rp} 3.000 .000$,- dengan penyusutan Rp 500.000,- sehingga nilai buku Rp 2.500.000,- dan kendaraan seharga $\mathrm{Rp}$ 16.000.000,- akumulasi penyusutan sebesar Rp 2.000.000,- setiap tahunnya sehingga nilai buku sebesar Rp 14.000.000,-

\section{Service Jam}

\section{LAPORAN LABA RUGI SERVIS JAM 31 Desember 2015}

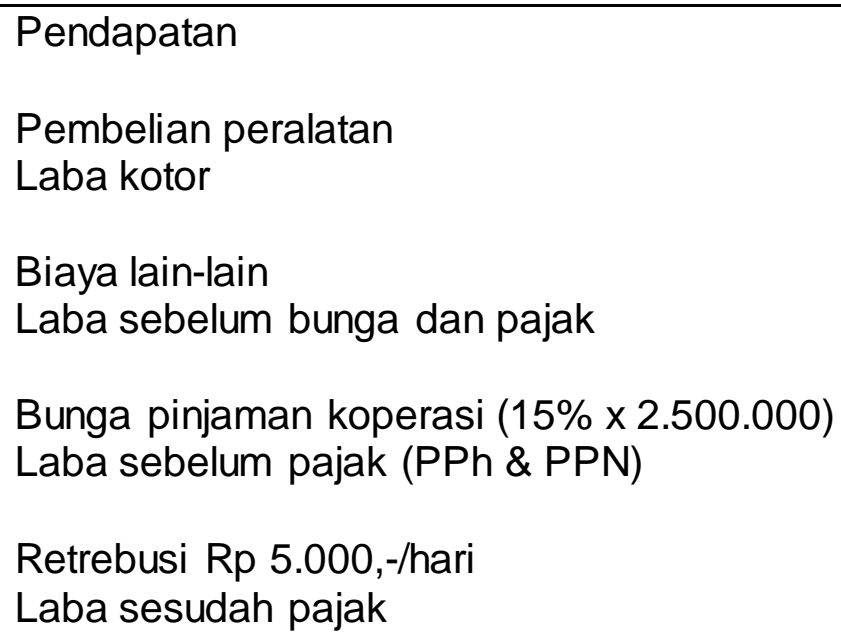

$$
\begin{array}{cr}
R p & 108.000 .000,- \\
R p & 50.000 .000- \\
\hline R p & 58.000 .000,- \\
R p & 7.200 .000- \\
\hline R p & 50.800 .000,- \\
R p & 375.000- \\
\hline R p & 50.425 .000,- \\
R p & 1.800 .000- \\
\hline R p & 48.625 .000,-
\end{array}
$$

Laporan laba rugi untuk usaha service jam tahun 2015 di atas dapat dirinci dimana : Pendapatan, yaitu jumlah service jam yang didapat $\mathrm{x}$ harga 1 buah jam yang disservice x 360 hari yaitu 20 x Rp $15.000=\operatorname{Rp} 300.000 \times 360$ sehingga pendapatan service jam tahun 2015 sebanyak = Rp 108.000.000. Untuk pembelian peralatan $\mathrm{Rp}$ 50.000.000. Sehingga pada service jam tahun 2015 dapat memperoleh laba sebesar Rp 48.625.000,-.
Service jam dalam menjalankan suatu kegiatan usahanya dapat dilihat dalam laporan neraca tahun 2015 adalah sebagai berikut : 
NERACA SERVIS JAM

31 Desember 2015

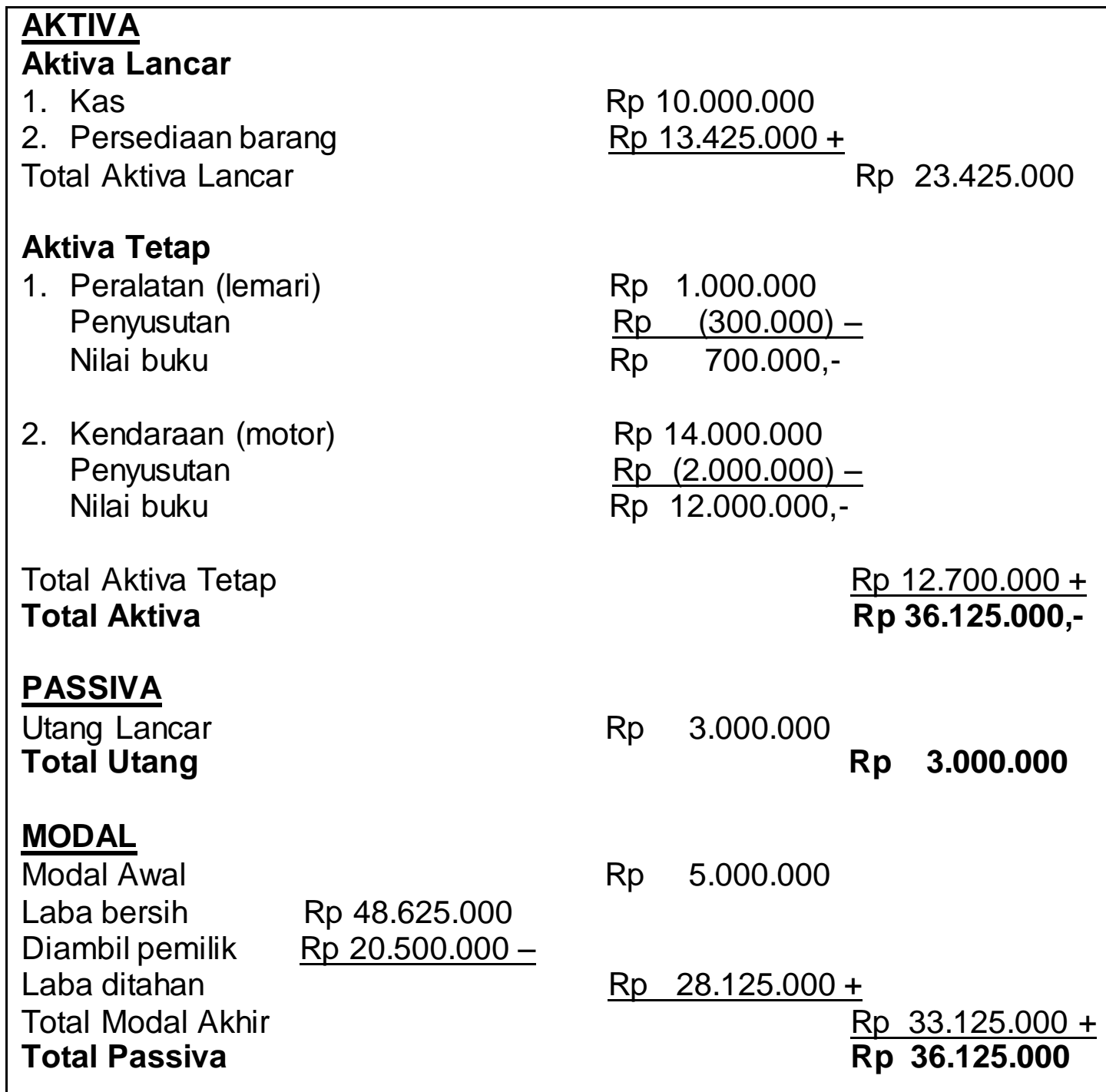

Pada service jam tahun 2015 memiliki total passive sebesar Rp 36.125.000 terdiri atas utang koperasi Rp 3.000.000 dan laba bersih sebesar Rp 48.625.000 kemudian diambil pemilik sebesar Rp 20.500.000 sehingga saldo laba ditahan sebesar Rp 28.125.000, total asset sebesar Rp 36.125.000 terdiri atas persediaan barang senilai $\mathrm{Rp}$ 13.425.000 peralatan Rp 1.000.000 penyusutan $\mathrm{Rp}$ 300.000 sehingga nilai buku Rp 700.000 kendaraan bermotor $\mathrm{Rp} \quad 14.000 .000$ dengan penyusutannya sebesar Rp 2.000.000 dengan nilai buku Rp 12.000.000 dan kas sebesar Rp 10.000.000.

\section{Rentabilitas Ekonomi (RE)}

Rumus untuk mencari rentabilitas ekonomi adalah sebagai berikut :

Rentabilitas ekonomi $=\frac{\text { Laba Bersih }}{\text { Total Aktiva }}$ 
Rasio Rentabilita Ekonomi

Pdg.Makanan, Pdg.Logam dan Service Jam

\begin{tabular}{|l|c|c|c|}
\hline \multicolumn{1}{|c|}{ Pertahun } & $\begin{array}{c}\text { Laba Bersih } \\
\text { Rp }\end{array}$ & $\begin{array}{c}\text { Total Aktiva } \\
\text { Rp }\end{array}$ & $\begin{array}{c}\text { Persentase } \\
(\%)\end{array}$ \\
\hline Pdg. Makanan & 81.910 .000 & 66.910 .000 & 1,22 \\
Pdg. Logam & 64.500 .000 & 49.500 .000 & 1,303 \\
Service Jam & 48.625 .000 & 36.125 .000 & 1.346 \\
\hline
\end{tabular}

$$
\begin{aligned}
\text { Pedagang Makanan } & =\frac{81.910 .000}{66.910 .000} \times 100 \% \\
& =1,22 \% \\
\text { Pedagang Logam } & =\frac{64.500 .000}{49.500 .000} \times 100 \% \\
& =1,303 \% \\
\text { Service Jam }= & \frac{48.625 .000}{36.125 .000} \times 100 \% \\
= & 1,346 \%
\end{aligned}
$$

Rentabilitas Modal Sendiri

Pdg.Makanan, Pdg.Logam, dan Service Jam
Jadi, dari analisis di atas pada ketiga pedagang kaki lima dimana persentase pada pedagang makanan mencapai $1,22 \%$ dengan laba bersih Rp 81.910.000 dan pedagang logam mencapai $1.303 \%$ dengan laba bersih $\mathrm{Rp}$ 64.500.000 dan service jam mencapai 1,346\% dengan laba bersih $\mathrm{Rp}$ 48.625.000.

\section{Rentabilitas Modal Sendiri (ROE)}

Rumus untuk mencari rentabilitas modal sendiri adalah sebagai berikut :

$\begin{aligned} & \text { Rasio Rentabilitas } \\ & \text { modal sendiri }\end{aligned}=\frac{\text { Laba Bersih }}{\text { Modal sendiri }} \times 100 \%$

Modal sendiri

\begin{tabular}{|l|c|c|c|}
\hline \multicolumn{1}{|c|}{ Tahun 2015 } & $\begin{array}{c}\text { Laba Bersih } \\
\text { Rp }\end{array}$ & $\begin{array}{c}\text { Modal Sendiri } \\
\mathbf{R p}\end{array}$ & $\begin{array}{c}\text { Persentase } \\
\mathbf{( \% )}\end{array}$ \\
\hline Pdg.Makanan & 81.910 .000 & 10.000 .000 & 8,191 \\
Pdg.Logam & 64.500 .000 & 10.000 .000 & 6,45 \\
Service Jam & 48.625 .000 & 5.000 .000 & 9,725 \\
& & & \\
\hline
\end{tabular}

$$
\begin{aligned}
\text { Pedagang makanan } & =\frac{81.910 .000}{10.000 .000} \times 100 \% \\
& =8,191 \% \\
\text { Pedagang Logam } & =\frac{64.500 .000}{10.000 .000} \times 100 \% \\
& =6,45 \% \\
\text { Service Jam } & =\frac{48.625 .000}{5.000 .000} \times 100 \% \\
& =9,725 \%
\end{aligned}
$$

Jadi, dari analisis di atas pada ketiga pedagang kaki lima dimana persentase pedagang makanan mencapai 8,191\% dengan laba bersih $\mathrm{Rp}$ 81.910 .000 dan pedagang logam mencapai 6,45\% dengan laba bersih Rp 64.500 .000 dan service jam mencapai 9,725\% dengan laba bersih $\mathrm{Rp} R \mathrm{p}$ 48.625 .000

\section{Rumus Rasio Solvabilitas}

Rumus Rasio Solvabilitas untuk mencari rasio total utang terhadap total harta adalah 
sebagai berikut :

$$
\begin{aligned}
& \text { Rasio total utang } \\
& \text { terhadap total harta }
\end{aligned}=\frac{\text { Total Harta }}{\text { Total Utang }}
$$

Laporan Keuangan Rasio Solvabilitas untuk Rasio total utang terhadap total harta tahun 2015 pada pedagang kaki lima yaitu pedagang makanan, pedagang logam, dan service jam adalah sebagai berikut :

\section{Laporan Keuangan Rasio Solvabilitas Untuk Rasio Total Utang Terhadap Total Harta Pdg.Makanan, Pdg.Logam, dan Service Jam}

\begin{tabular}{|l|c|c|}
\hline \multicolumn{1}{|c|}{ Tahun 2015 } & Harta (Rp) & Utang (Rp) \\
\hline $\begin{array}{l}\text { Pdg. } \\
\text { Makanan }\end{array}$ & Rp 43.910.000 & Rp 7.000.000 \\
\hline Pdg. Logam & Rp 33.000.000 & Rp 15.000 .000 \\
\hline Service Jam & Rp 23.425.000 & Rp 3.000.000 \\
\hline
\end{tabular}

Pedagang Makanan :

$$
\begin{aligned}
\text { Pada pedagang makanan } & =\frac{43.910 .000}{7.000 .000} \\
& =6,27 \mathrm{kali}
\end{aligned}
$$

Artinya, jumlah aktiva lancar sebanyak 6,27 kali utang lancar, atau setiap 1 rupiah utang lancar dijamin oleh Rp 6,27 kali harta lancar atau 6,27 : 1 antara aktiva lancar dengan utang lancer.

$$
33.000 .000
$$

Pedagang Logam $=$

$$
\begin{aligned}
& 15.000 .000 \\
&=\quad 2,2 \mathrm{kali}
\end{aligned}
$$

Artinya, jumlah aktiva lancar sebanyak 2,2 kali utang lancar, atau setiap 1 rupiah utang lancar dijamin oleh $\mathrm{Rp}$ 2,2 kali harta lancar atau 2,2 : 1 antara aktiva lancar dengan utang lancar.
23.425 .000

Pada Service Jam $=$

$$
\begin{array}{r}
3.000 .000 \\
=7,81 \text { kali }
\end{array}
$$

Artinya, jumlah aktiva lancar sebanyak 7,81 kali utang lancar, atau setiap 1 rupiah utang lancar dijamin oleh Rp 7,81 kali harta lancar atau 7,81:1 antara aktiva lancar dengan utang lancar. Jika ratarata usaha untuk current ratio adalah 1,10 kali, maka keadaan pedagang kaki lima pada Pedagang Makanan, Pedagang Logam, Service Jam sangat baik karena di atas rata-rata.

\section{Rasio Total Utang Terhadap Modal Sendiri}

Rumus untuk Rasio Total Utang terhadap Modal Sendiri adalah sebagai berikut :

$$
\begin{aligned}
& \text { Rasio Total Utang terhadap }= \\
& \text { Modal Sendiri }
\end{aligned}
$$

Laporan Keuangan Rasio Solvabilitas untuk Rasio Total Utang terhadap Modal Sendiri pada pedagang kaki lima tahun 2015, yaitu pedagang makanan, pedagang logam, dan service jam adalah sebagai berikut :

Komponen Laporan Keuangan Rasio Solvabilitas Untuk Rasio Total Utang terhadap Modal Sendiri

Pdg.Makanan, Pdg.Logam dan Service Jam

\begin{tabular}{|c|c|c|}
\hline $\begin{array}{c}\text { Pedagang } \\
\text { Kaki Lima } \\
2015\end{array}$ & $\begin{array}{c}\text { Utang } \\
(\mathrm{Rp})\end{array}$ & $\begin{array}{c}\text { Modal Sendiri } \\
(\mathrm{Rp})\end{array}$ \\
\hline Pdg. Makanan & 7.000 .000 & 10.000 .000 \\
\hline Pdg. Logam & 15.000 .000 & 10.000 .000 \\
\hline Service Jam & 3.000 .000 & 5.000 .000 \\
\hline
\end{tabular}




$$
\begin{aligned}
\text { Pada pedagang makanan } & =\frac{7.000 .000}{10.000 .000} \\
& =0,7 \mathrm{kali} \\
\text { Pada pedagang logam } & =\frac{15.000 .000}{10.000 .000} \\
& =1,5 \mathrm{kali} \\
\text { Pada service jam }=\quad & \frac{3.000 .000}{5.000 .000} \\
= & 0,6 \mathrm{kali}
\end{aligned}
$$

Hasil analisa Rasio Solvabilitas untuk Rasio Total Utang terhadap Modal Sendiri pada pedagang makanan, pedagang logam, dan service jam di tahun 2015, bahwa jumlah utang yang dibiayai pada pedagang makanan dengan 0,7 kali modal sendiri, pedagang logam jumlah utang yang dibiayai 1,5 kali modal sendiri, dan service jam jumlah utang yang dibiayai 0,6 kali dari modal sendiri. Artinya, bahwa kemampuan modal pinjaman pada ketiga pedagang kaki lima di atas memperoleh laba yang cukup besar. Hal ini menunjukkan bahwa penggunaan modal pinjaman sangat baik.

\section{SIMPULAN}

Berdasarkan pembasahan hasil penelitian yang telah diuraikan oleh peneliti di atas, maka dapat disimpulkan bahwa; Usaha yang dikelola oleh pedagang kaki lima di kota palopo dengan bantuan modal pinjaman mampu memperoleh laba bersih yang cukup untuk membantu memenuhi kebutuhan hidup pedagang kaki lima termasuk untuk menambah modal usahanya, bahkan mampu menambah jumlah harta (aktiva) bagi pedagang kaki lima di kota Palopo.

\section{DAFTAR PUSTAKA}

Arifin Sitio dan Tamba Halomoan. 2001. Koperasi: Teori dan praktik. Jakarta: Erlangga.

Baswir, Revrisond, 2000, Koperasi Indonesia, Yogyakarta: BPFE-UGM.

Joel G Siegel, Jae K. Shim. 1999. Kamus Istilah Akuntansi Dialih bahasakan Oleh Moh. Kurdi, Cetakan ke3, Jakarta : Alex Media Kompotindo.

Riyanto, Bambang. Dasar-Dasar Pembelanjaan Perusahaan. Yokyakarta: BPFE, 1995.

Kasmir. 2003. Bank Lembaga Keuangan Lainnya. Jakarta: PT Raja Grafindo Persada.

Kasmir. 2008, Bank dan Lembaga Lainnya, Edisi Revisi. PT. Raja Grafindo Persada

Suhardjo. 2003. Manajemen Perkreditan Usaha Kecil Menengah, Yogyakarta : UPP AMP YKPN

Siregar, Doli 2004. Manajemen Aset, Strategi Pemetaan Konsep Pembangunan Berkelanjutan secara Nasional dalam Konteks Kepala Daerah sebagai CEO'S pada Era Globalisasi dan Otonomi Daerah, PT. Gramedia Pusaka Utama, Jakarta.

Todaro, M P dan Smith. 2006. Pembangunan Ekonomi: Edisi Kesembilann. Erlangga, Jakarta.

Manurung Jonni J., dan Adler H. Manurung, 2009. Ekonomi dan Keuangan dan Kebijakan Moneter. Cetakan Pertama. Jakarta: Selemba Empat.

Suad Husnan. (1998). Manajemen Keuangan Teori dan Penerapan (Keputusan Jangka Pendek) Buku 2. Yogyakarta: BPFE..

Undang-Undang Dasar 1945 Pasal 28 Tentang Hak Asasi Manusia.

Undang-Undang Republik Indonesia Nomor 25 Tahun 1992, Tentang Perekonomian. 
Hasibuan, Malayu,2001. Dasar-dasar Perbankan, PT. Bumi Aksara, Jakarta.

Hanafi,MM, dan Halim, Abdul. 2009. Analisis Laporan Keuangan, Edisi Keempat. Yogyakarta : Sekolah Tinggi Ilmu Manajemen YKPN.

Mulyanto. 2007. Konsep Sektor Informal : Pedagang Kaki Lima. Http: //s santoso.blogspot.com/2008/07/konsep sektor - informal - pedagang kaki lima_28.html diakses pada tanggal 28 Agustus 2011

Riduwan, 2006. Dasar-dasar Statiska. Cetakan Kelima, Bandung : Alfabeta.

Mazumdar, D. (1991). Sektor Informal di kota : Analisis Empiris Terhadap Data dari berbagai negara di dunia ketiga. Urbanisasi, Pengangguran, dan sektor informal di kota. (C. Manming \& T. N Effendi). Jakarta : Yayasan Obor Indonesia

Winardi. 1992. Ekonomi Mikro. Bandung: Bandar Maju..

Hero Sutojo. 1999. Profit Usaha Kecil dan Kebijakan kredit Perbankan di Indonesia, Lembaga Manajemen REUI, Jakarta. 